Regent's Park, will, I think, be satisfied that they may again be so, and that in temper, docility, and working power, they would be equal, if not superior, to the Indian elephant.

Through the medium of the columns of NATURE, perhaps an impetus may be given to a matter that is certainly worthy of consideration, and may elicit further remarks from some of the Indian Keddah officers, who are practically experienced in the mode of dealing with elephants. It is, at all events, worthy of Sir Bartle Frere's consideration.

J. FAYRER

\section{SYNCHRONISED CLOCKS}

R AILWAYS, among many other services which they R have rendered, have made us more particular about keeping our watches and clocks in accordance with some common standard of time, and during the past few years various systems have been tried for the distribution of a standard time from a common centre-in this country Greenwich Observatory. For purposes of public life it is more important to have all the public and even private time-pieces of a country set according to one standard, than that they should show the correct local time. The latter can easily be ascertained by any one who desires it, if he can be sure of knowing the exact Greenwich time. Of all the systems that have been tried for ordinary public use, that recently organised by Messrs. Barraud and Lund, of Cornhill, seems to us to answer all the requisite conditions. We had the pleasure the other day of inspecting the arrangements made by Messrs. Barraud and Lund for the distribution of Greenwich time from Cornhill as a centre, and we are bound to say that the perseverance and ingenuity displayed deserve success, and we believe that wonderful success has been obtained. Messrs. Barraud and Lund have spared no pains and no expense to perfect their system, which, as a practical and widely useful application of science, is full of instruction.

Any system for the public service of time-signals by synchronising currents which lays claim to approximate perfection, naturally divides itself into three distinct departments; $\mathbf{r}$. The maintenance of a standard timekeeper at absolutely correct Greenwich mean time; 2 . The distribution of the time at hourly intervals with the needful apparatus for testing the work done; and last but not least, the particular means adopted to enable the time currents to control or set the various clocks in circuit to true time. As to the standard adopted by Messrs. Barraud and Lund, and which is in direct communication with Greenwich, this is a mercurial regulator of the very best construction with a Graham dead-beat escapement, having the contact springs for the time-current between the dial and upper plate, the dial being pierced so as to allow free access to all parts of this mechanism without otherwise stopping or interfering with the regulator. However excellent such a time-keeper may be some error will always exist; it will have a daily rate however small, and it becomes important that this error should be corrected at least once a-day. In order that this may be effected without actually using any physical connection, Messrs. Barraud and Lund have adopted the following method :- A permanent bar-magnet about 6 inches long, is secured to the pendulum-rod, so as to vibrate about $\frac{1}{32}$ of an inch from a resistance-coil fastened to the case by a projecting bracket; a current of electricity passing through this coil, accelerates or retards the vibrations of the pendulum according as the current sent is positive or negative, and the power of the current is adjusted to give one second of infuence for one hour of duration. The wires of this adjusting current are connected with a commutator, a small instrument about two inches by three-and-a-half, having three holes-that in which a plug is normally placed when no effect is required to be produced, a second marked "fast," and a third " slow," for the reception of the plug, according as the standard requires to be accelerated or retarded. In order to secure the continuance of the current for a period neither longer nor shorter than will produce the desired result, a small ordinary clock is interposed between the commutator and

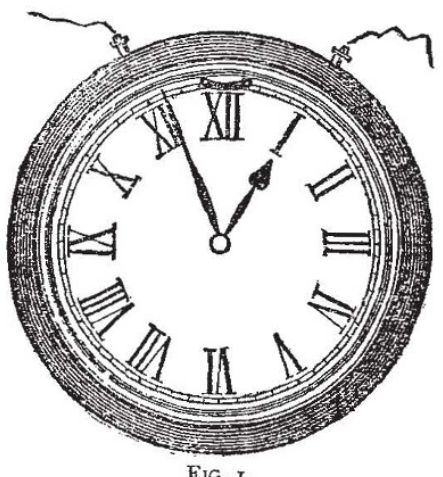

the standard clock. This clock answers a double purpose; it has no hour hand, but only a minute hand, which stands normally at twelve, in which position the clock is "stopped," and no current can pass through to the resistance coil. The plug having first been placed in the "fast" or "slow" hole, as occasion may require, the

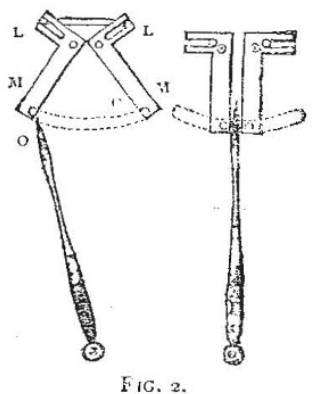

clock is set back, say one half-hour for half a second crror of the standard. The mere fact of setting back this hand, starts the small clock and closes the current at the same moment, continuing to keep a closed current, till the hand returns to 12 , when it again breaks contact and stops itself. It will thus be seen that one operation alone

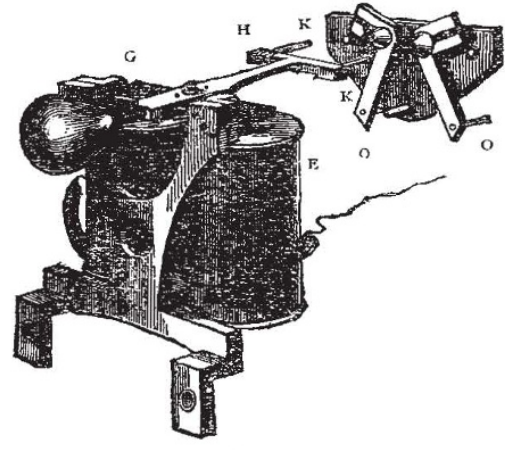

FIG. 3.

is required to set the standard, the whole action automatically ceasing the moment the standard is "to time."

The "distributor" is, in fact, a compound "relay" for twelve circuits, it having been determined to use independent batteries for each line wire in preference to split currents, as used in the chronopher at St. Martin's-le- 
Grand. The appearance of this "distributor" is very much like a miniature cart-wheel, about five inches in diameter, inclosed in a circular glass-case, the spokes being the twelve contact springs and the nave a small insulated table whicb, when the standard automatically closes the contact springs of the time-wire at the exact sixtieth second every hour, is instantly carried down upon and closes the twelve pair of contact-springs connecting the twelve line-wires with their batteries.

Many interesting methods have been adopted for testing and other purposes of maintenance, but we have only space to mention two. One is for the purpose of warning in case of a break-down. This consists of an ordinary electric clattering bell, with a small clock attached, and also connected with the line-wire. So long as the timecurrents pass regularly through this instrument the alarmbell remains silent; but five minutes after the failure of any time signal to pass out upon its duty, the alarm-bell begins to ring violently, continuing to do so for five minutes, and then leaving a small drop indicator, showing on which line the break-down has occurred. There is only one alarm-bell, but each line requires its attendant little timepiece (which, being "synchronised" by the passing current, never can be wrong) and drop indicator. The other instrument is an alarum answering the following important purpose :-A break-down being reported, a plug is placed in a "bridge" corresponding to the number of the line, which causes a very weak current (too weak to affect any of the synchronisers) to pass out along the line for the use of the linesman when searching for the fault; this found and repaired it is important that the plug should be immediately removed : to call attention at the office in Cornhill the linesman has only to break contact at the nearest clock anywhere on the line to set the alarum going in the instrument room, when, the plug being removed, the alarum is shunted off and the line clear for work.

We now come to the chief specialty of the system of Messrs. Barraud and Lund, namely, the synchroniser. This is an automatic finger-and-thumb action, brought to bear hourly on the minute-hand, and bringing it, whether fast or slow, "to time." Each synchroniser is complete in itseif, and is simply screwed behind the dial of the clock to be synchronised. It is as follows:-

Two levers carrying pins, and representing the human finger and thumb, project through a slot in the dial(Fig. I), and either. close upon the end of the minute hand itself, or upon a small block fastened to it underneath; the two levers have at their other end slots in which two pins work, projecting from the keeper of an electro-magnet, which, when magnetised at the given moment by the closing of the contact springs on the standard clock, draws the pins together, and sets the hand to time. A reference to Figs. 2 and 3 will at once make the modus operandi clear. $\mathrm{E}$ is an ordinary electro-magnet, $\mathrm{G}$ the keeper, carrying a bar, $\mathrm{H}$, and two projecting pins, $\mathrm{K} \mathrm{K}$; these act in slots $L L$ in the levers $M M$, from the ends of which project the pins oo (representing the human finger and thumb); the passage of the current draws down the keeper and bar, acts upon the lever's $M M$, closing them upon the minute hand of the clock and setting it, whether fast or slow, to time.

The following are some of the special advantages claimed for this system :- - . That any number of clocks, few or many, of any varying sizes, can be synchronised to any agreed standard time-keeper. 2. That the mechanism is, when not in its momentary use, entirely detached from the works of the clock. 3. That it can be applied to existing clocks by simply being screwed in its place, and a narrow slit cut in the dial. 4. That any failure in the transmission of the time-current leaves the clock going in the ordinary way, to be "set to time" by the next completed current. 5. That the clocks are kept to time, whether having otherwise either a gaining or losing rate, even if such rate amounts to many minutes a day.

It will seen from the above description that the system owes its success not to the discovery or application of any new fact, such as that for which such eager search is now being made to secure a perfect electric light, but from the simplicity and efficiency of the synchronisers, and their adaptability to every kind and size of clock. By the simple expedient of winding the coils of all the instruments with one size wire, any number, all of varying sizes and powers, can be connected up in circuit. In the City circuit alone, which is wholly controlled by the standard at 4I, Cornhill, 108 clocks on eleven different lines of an aggregate length of ten miles, and connecting over eighty different establishments, are efficiently kept to true time. Many more, we believe, are kept to time, not only in other widely distant parts of London, but in various parts of the country; for the latter purpose Messrs. Barraud and Lund have a contract with the Postal Telegraph Department for the delivery of time currents at certain hours each day. There is now no reason why all our public clocks at least should not be included within the correcting power of this system, and lead us astray no longer.

\section{THE TELEPHONE, ITS HISTORY AND ITS
RECENT IMPROVEMENTS} III.

\section{The Carbon Telephone}

T the columns of this journal (NATURE, vol. xvii. p. 5 I2) the present writer remarked in the early part of the year " that it was unlikely the telephone of the future would employ the voice to generate the driving power, as it does in the magneto-telephone, but only to modulate the flow of a current obtained by coarser means. It is in this direction that Mr. Edison is working, and his practical triumphs in the past are the earnest of success to those excellent telephonic investigations wherein he has already won an enduring fame." Since those words were written Mr. Edison has brought his telephonic experiments to so successful an issue that his carbon transmitter and his new receiver leave little to be desired in electric telephony, except the automatic record of the received speech, and this, it is not impossible, may ere long be accomplished.

The object Mr. Edison sought to attain was a variation in the resistance of the circuit proportional to the motions of the vibrating diaphragm of the transmitter. Gray employed for this purpose a liquid resistance, but owing to the fact that all suitable liquids are decomposed by the current, Edison abandoned them and tried solid conductors. He remarks in Prescott's work on the telephone :-

"In the spring of 1876 , and during the ensuing summer, I endeavoured to utilise the great resistance of thin films of plumbago and white Arkansas oil-stone, on ground glass, and it was here that I first succeeded in conveying over wires many articulated sentences."

A spring attached to the vibrating diaphragm was arranged so as to cut in and out of the circuit more or less of the plumbago film. But the results were not very favourable. In January, 1877 , a new device occurred to Edison, namely, the employment of a peculiar property which semi-conductors have, of varying their resistance under pressure. ${ }^{1}$ For this purpose

I Continued from p. 14.
2 We have already considered in a previous article the historical facts connected with this discovery, and therefore it will be needless to refer to this point here. A reference to the Journal Télégraphique of Berne for 1874, wherein it was asserted M. Clérac had anticipated the use Mr. Edison has made of the varying resistance of carbon dust under varying pressures, fully application is not due to M. Clérac at all, who simply used permanently compressed carbon diust as a rheostat. 